\title{
Cognitive Behavioral Intervention Program Aimed at Patients Tributary for Cardiopulmonary Bypass Surgery
}

\author{
Carlos Gonzalo Figueroa-López¹, Santiago Rincón-Salazar'1, Gloria Mitzi Guijosa-Neri'1, \\ María José Rodales-Feria1, Carlos Riera-Kinkel², Bertha Ramos-Del Río \\ ${ }^{1}$ Psychology, FES Zaragoza UNAM, México \\ ${ }^{2}$ Division Cardiothoracic Surgery, Hospital de Cardiología, Centro Médico Nacional Siglo XXI, Instituto Mexicano del Seguro \\ Social, Mexico City, Mexico \\ Email: carlos.figueroa@zaragoza.unam.mx
}

How to cite this paper: Figueroa-López, C. G., Rincón-Salazar, S., Guijosa-Neri, G. M., Rodales-Feria, M. J., Riera-Kinkel, C., \& Río, B. R.-D. (2022). Cognitive Behavioral Intervention Program Aimed at Patients Tributary for Cardiopulmonary Bypass Surgery. Open Journal of Social Sciences, 10, 46-58. https://doi.org/10.4236/jss.2022.102002

Received: December 28, 2021

Accepted: February 8, 2022

Published: February 11, 2022

Copyright (c) 2022 by author(s) and Scientific Research Publishing Inc. This work is licensed under the Creative Commons Attribution International License (CC BY 4.0).

$\underline{\text { http://creativecommons.org/licenses/by/4.0/ }}$ (c) (i) Open Access

\begin{abstract}
Objective: The present study proposes a psychological preparation program with a cognitive behavioral intervention to reduce levels of anxiety and depression in addition to modifying the coping style of patients with heart disease who will undergo a surgical intervention with cardiopulmonary bypass. Method: A quasi-experimental pre-test-posttest study was carried out with a control group. 91 patients were evaluated prior to undergoing cardiac cardiopulmonary bypass surgery, of which 16 were selected for this study, 8 participated in psychological treatment and 8 patients were selected for the control group. Instruments: Hospital Anxiety and Depression Scale and the Questionnaire for Coping with Injuries and Health Problems. Results: Differences were found in the anxiety and depression scores of the experimental group, although these results were not statistically significant. On the other hand, a significant difference was found as a treatment effect between the groups in favor of the experimental group in the greater use of the Palliative coping style $(p=0.05)$ and less predominance of the Emotional style $(p=0.05)$. Conclusion: It is essential that the psychologist specialized in behavioral cardiology develops and carries out interventions so that the patient develops cognitive, emotional and coping strategies for the management of anxiety and depression.
\end{abstract}

\section{Keywords}

Cardiopulmonary Bypass Surgery, Anxiety, Depression, Coping Styles, Cognitive Behavioral Intervention 


\section{Introduction}

Cardiovascular diseases are defined as a group of disorders of the heart and blood vessels. They are the main cause of death in Mexico and in the world; according to the Instituto Nacional de Estadística y Geografía (INEGI) 20.8\% of the Mexican population died due to cardiovascular disease between January and August 2020, exceeding the percentage of cause of death due to COVID-19, which was 15.9\% (INEGI, 2021; OMS, 2020).

Due to the magnitude in which these pathologies occur and the monetary cost that they represent for the health sector, it is important to develop treatments and interventions that improve the quality of life of these patients. One of these alternatives is Cardiopulmonary Bypass Surgery, which is defined as "any system in which blood is drained out of the body, replacing the functions of the heart and lungs" (Reyes \& González, 2002: p. 38) with the use of a cardiopulmonary bypass machine allowing the heart to remain still while the surgeon repairs the damage of the heart.

The emotional comorbidities, anxiety, depression and coping, in tributary patients of Cardiopulmonary Bypass Surgery, are experienced at different levels in each patient. For example, anxiety, which according to Crandall, Halterman and Mackner (2007) is defined as an involved emotional reaction in the processes of adaptation to real or imaginary adverse events, which prepares the organism to react to this situation. In this article, obtaining a score greater than 3 on the anxiety subscale of the HADS (Zigmond \& Snaith, 1983) indicates the presence of the symptoms.

Depression is a mood disorder with feelings of sadness, low self-esteem, pessimistic attitude, loss, anger or frustration that interfere with the individual's daily life for a prolonged period of time (Snaith, 2003). Obtaining a score greater than 3 on the depression subscale of the Hospital Anxiety Depression Scale (HADS) (Zigmond \& Snaith, 1983) indicates the presence of symptoms.

Lazarus and Folkman (1986) define coping as constantly changing cognitive and behavioral efforts developed to handle specific external or internal demands that are evaluated as overflowing the individual's resources. The Coping with Health Injuries and Problems Scale (Endler, Parker, \& Sommerfeldt, 1998) evaluates palliative, instrumental, emotional and distraction coping styles.

Before the perspective of a cardiopulmonary bypass surgery, patients experience disruptive emotions since it represents the possibility of recovering health, but it is also a stressful event that produces emotional disorders (fear of not waking up from anesthesia, pain, separation from family and home) and negative impact on quality of life (Beresnevaitè et al., 2016).

There are various studies that show the relationship between the psychosocial risk factors (anxiety, depression, quality of life, stress) and cardiac disease. Talavera-Peña et al. (2020) show that a psychoeducational intervention reduces anxiety and depression levels in tributary patients of Cardiopulmonary Bypass Surgery. Reavell et al. (2018) carry out a meta-analysis of various studies in 
which cognitive behavioral therapy is applied, demonstrating effectiveness in reducing anxiety and depression during the follow-up of patients with cardiovascular disease.

Niknejad et al. (2019), in a study of 70 patients who were candidates for coronary artery bypass graft, observed that the intervention group reported lower levels of anxiety before surgery. Ramesh et al. (2016) applied a pre and postoperative education program in patients undergoing cardiac surgery and found a statistically significant difference between the group of patients who received the intervention program and the control group, decreasing anxiety, depression and pain levels in the postoperative evaluation. Castillero (2007), created a psychological program for patients tributary of cardiac surgery. He evaluated sleep disorders, depression and anxiety and carried out a psychoeducational program with breathing techniques and providing information about the surgical procedure.

The non-pharmacological interventions that are most effective in the treatment of emotional comorbidity are the psychological preparation programs. These are defined as a set of cognitive-behavioral psychological strategies focused on reducing anxiety and psychological stress associated with surgical medical procedures (Rodríguez, 2000). In the case of patients subject to cardiopulmonary bypass surgery, the goals of the program would be to give information about the disease to the patient, to control anxiety and depression levels, to develop strategies for solving problems related to their surgery, to reduce post-surgical pain and to provide training in the acquisition of beneficial instrumental.

The aim of this study is to determine the efficacy of a psychological preparation program with a cognitive behavioral intervention to reduce levels of anxiety and depression in addition to modifying the coping style of patients with heart disease tributary of a surgical intervention with cardiopulmonary bypass.

\section{Method}

A quasi-experimental pretest-posttest study with a control group was carried out; patients' candidates for cardiac surgery by cardiopulmonary bypass with a diagnosis of valvular or ischemic heart disease were selected intentionally in the High Specialty Medical Unit of Cardiology of the National Medical Center (IMSS) in Mexico City. The criteria for selecting patients were: literate men and women over 40 years of age without a psychiatric diagnosis of anxiety or depression, who had not requested psychological support during their medical check-ups or from the moment of the evaluation, and who had no other diagnoses of chronic health diseases in advanced stage such as cancer or renal failure. Those who reported taking medications such as anxiolytics and antidepressants, and those who had at least two absences or incomplete evaluations, were excluded from the study.

Between May 2019 and March 2020, patients who would undergo cardiopul- 
monary bypass surgery were invited to participate in the study. One month before the surgical procedure, 91 patients answered the psychological evaluation of anxiety, depression and coping styles. The participants were randomly divided into two groups, only 16 patients agreed to participate in the cognitive behavioral intervention sessions, those who did not accept were invited to be part of the control group (Figure 1 shows the flow of participants throughout the study). The sample for the final analysis consisted of 8 patients from the experimental group who ended up in psychological treatment and post-evaluation, and 8 patients from the control group were selected according to age and gender similar to the experimental group.

\section{Independent variable}

Cognitive behavioral intervention: Set of cognitive-behavioral psychological strategies focused on reducing anxiety and psychological stress associated with surgical medical procedures.

\section{Dependent variables}

\section{1) Anxiety}

Conceptual definition: Emotional reaction involved in the adaptation processes to real or imaginary adverse events, which prepares the organism to react to this situation (Crandall, et al., 2007).

Operational definition: score in the HADS anxiety subscale indicates the presence of symptoms. The results can be in a range of 0 to 21 .

Measurement level: interval.

\section{2) Depression}

Conceptual definition: Mood disorder with feelings of sadness, low self-esteem, pessimistic attitude, loss, anger or frustration interfere with the individual's daily life for a prolonged period of time (Snaith, 2003).

Operational definition: score in the HADS depression subscale. The results can be in a range of 0 to 21 .

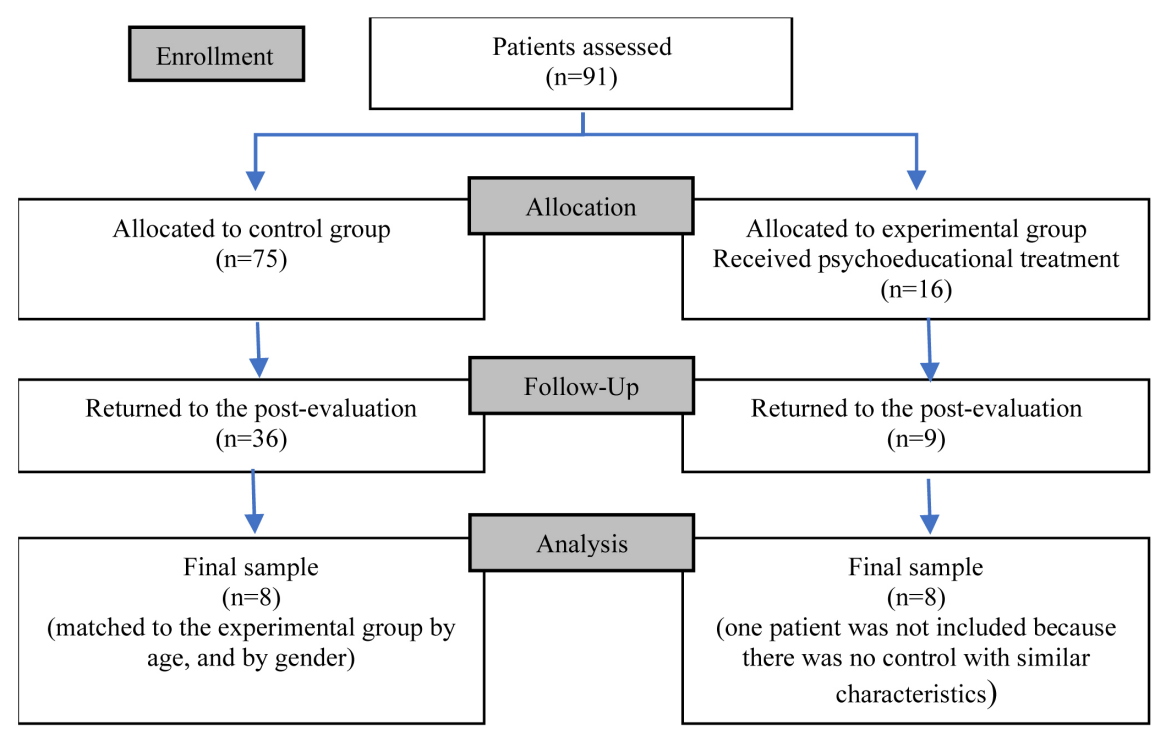

Figure 1. Allocation's flowchart of participants to experimental and control group. 
3) Coping

Conceptual definition: Constantly changing cognitive and behavioral efforts that are developed to handle specific external or internal demands that are evaluated as surplus or overflowing the individual's resources.

Operational definition: it will be measured through the Inventory of Coping with Injuries and Health Problems (CHIP), which indicates, according to the highest score, the most used coping style and the least used according to the lowest score. The coping styles are: Distraction, Palliative, Instrumental and Emotional.

\subsection{Instruments}

Sociodemographic data (age, sex, marital status, among others) were obtained via a questionnaire.

In the psychological evaluation the following instruments were used:

- HADS (Zigmond \& Snaith, 1983). It consists of 14 items divided into two subscales of seven items each with four response options in a Likert scale. Internal consistency using Cronbach's Alpha test was $\alpha=0.82$ for the anxiety scale and $\alpha=0.76$ for the depression scale.

- Questionnaire for Coping with Injuries and Health Problems (CHIP): Self-report inventory designed to identify the typical coping styles of an individual, it is composed of 32 items with a Likert-type 5-point scale that ranges from 1 (not at all) to 5 (a lot). It is divided into 4 coping scales: Distraction, Palliative, Instrumental, Emotional concern (Endler, et al., 1998).

\subsection{Procedure}

The research was divided into three stages: 1) Psychological pre-evaluation, 2) Psychological preparation program, 3) Psychological post-evaluation. These stages were carried out in six individual work sessions, each lasting 60 minutes. All patients were informed about the objective of the program, its activities, and benefits. Subsequently, they were invited to sign the Informed Consent and were assigned to the control or experimental group. In both groups, stages 1 and 3 (evaluation stages) were carried out, stage 2 the Cognitive Behavioral Program (CBP) was applied only in the experimental group.

Stages 1 and 3 comprise a psychological evaluation in which the anxiety, depression and coping scales were applied.

In Stage 2, the cognitive-behavioral program included three main topics which were ap-plied in 4 consecutive days: Psychoeducation of the disease (information about heart disease and the treatment to control it, emotional comorbidity and how to reduce anxiety, depression), problem solving technique (identification of problematic situation, elaboration of alternative solutions and appropriate application in the decision-making process aimed at the disease, surgery or its recovery) and training in relaxation skills (teaching and diaphragmatic breathing practice). 
The planning for each of the CBP sessions was as follows:

- Session 1: 20 minutes for disease psychoeducation, 20 minutes for problem solving technique, 20 minutes for relaxation practice.

- Session 2: review of the information from the previous session, review of the task, 20 minutes for the psychoeducation of the disease, 20 minutes for the problem-solving technique, 20 minutes for training.

- Session 3: review of the information from the previous session, review of the task, 20 minutes for the psychoeducation of the disease, 20 minutes for the problem-solving technique, 20 minutes for training.

- Session 4: review of the information from the previous session, review of the task, 20 minutes for the psychoeducation of the disease, 20 minutes for the problem-solving technique, 20 minutes for relaxation training and closure of the activities clarifying doubts on the information and activities provided.

At the end of the CBP the patients of both groups entered their cardiac cardiopulmonary bypass surgery and, approximately 5 to 7 days after the surgery, a post-evaluation was performed.

The data were analyzed with the statistical package SPSS v23. The bioethical principles of non-maleficence, beneficence, autonomy and justice, of the Helsinki declaration for medical research, were respected at all times.

\section{Results}

The mean age of the participants in the control group was 58.5 years (with a range between 41 and 74 years) and 59 years in the experimental group (with a range of 46 and 74 years). Both groups were made up of 3 women and 5 men, most of whom are married and with high school. The only difference in the sociodemographic data is in the type of occupation, where $50 \%$ of the patients in the control group are dedicated to the home, and $75 \%$ of the patients in the experimental group have some job (Table 1).

The control group had an average score $\mathrm{M}=4(\mathrm{SD}=3.02$, maximum score of 8 ) in the pretest, and an $\mathrm{M}=3.63$ ( $\mathrm{SD}=2.72$, maximum score of 9 ) for the posttest on the anxiety scale. In depression, these patients obtained an average score of the depression scale of $\mathrm{M}=1.5$ ( $\mathrm{SD}=1.41$, maximum score of 4 ) which corresponds to some degree or null depression in the pretest, and in the posttest of $1.75(\mathrm{SD}=1.28$, maximum score of 4$)$ equal corresponds to a null level (Table 2).

In the experimental group, in the pretest these patients obtained an $M=5.50$ $(\mathrm{SD}=3.29$, maximum score of 9 ) on the anxiety scale, and for the posttest an $\mathrm{M}$ $=2.88(\mathrm{SD}=2.29$, maximum score of 6$)$. In the pretest, an average score of the depression scale of $\mathrm{M}=3$ ( $\mathrm{SD}=2.73$, maximum score of 9 ) was obtained, which corresponds to a level of mild to moderate, and in the posttest of 2 ( $S D=1.77$, maximum score of 6) remained at the same level from mild to moderate (Table 2).

Table 3 shows no significant differences as a treatment effect between the groups in the level of anxiety, but there were significant differences in the 
Table 1. Sociodemographic characteristics of the participants assigned by group.

\begin{tabular}{|c|c|c|}
\hline & \multicolumn{2}{|c|}{ Group } \\
\hline & $\begin{array}{c}\text { Control } \\
\mathrm{n}(\%)\end{array}$ & $\begin{array}{c}\text { Experimental } \\
\mathrm{n}(\%)\end{array}$ \\
\hline Age $[\mathrm{Md}(\min -\max )]$ & $58.5(41-74)$ & $59(46-74)$ \\
\hline \multicolumn{3}{|l|}{ Sex } \\
\hline Woman & $3(37.5 \%)$ & $3(37.5 \%)$ \\
\hline Men & $5(62.5 \%)$ & $5(62.5 \%)$ \\
\hline \multicolumn{3}{|l|}{ Civil Status } \\
\hline Single & & $1(12.5 \%)$ \\
\hline Married & $8(100 \%)$ & $7(87.5 \%)$ \\
\hline \multicolumn{3}{|l|}{ Scholarship } \\
\hline Elementary school & $1(12.5 \%)$ & $1(12.5 \%)$ \\
\hline Middle school & $2(25.0 \%)$ & $1(12.5 \%)$ \\
\hline High school & $4(50.0 \%)$ & $5(62.5 \&)$ \\
\hline Bachelor's degree & $1(12.5 \%)$ & $1(12.5 \%)$ \\
\hline \multicolumn{3}{|l|}{ Occupation } \\
\hline Home & $4(50.0 \%)$ & $1(12.5 \%)$ \\
\hline Employee & $2(25.0 \%)$ & $6(75 \%)$ \\
\hline Retired & $2(25.0 \%)$ & $1(12.5 \%)$ \\
\hline \multicolumn{3}{|l|}{ Religion } \\
\hline Catholic & $8(100 \%)$ & $7(87.5 \%)$ \\
\hline Other & & $1(12.5 \%)$ \\
\hline
\end{tabular}

Note: $\mathrm{N}=16(\mathrm{n}=8$ for each group).

Table 2. Descriptive data of anxiety, depression and types of coping in the pretest and posttest for both groups.

\begin{tabular}{ccccc}
\hline & \multicolumn{2}{c}{ Pretest } & \multicolumn{2}{c}{ Postest } \\
\cline { 2 - 5 } & $\mathrm{M}(\mathrm{SD})$ & Range & $\mathrm{M}(\mathrm{SD})$ & Range \\
\hline Anxiety & & & & \\
Control & $4.00(3.02)$ & $0-8$ & $3.63(2.72)$ & $1-9$ \\
Experimental & $5.50(3.29)$ & $1-9$ & $2.88(2.29)$ & $0-6$ \\
Depression & & & & \\
Control & $1.50(1.41)$ & $0-4$ & $1.75(1.28)$ & $0-4$ \\
Experimental & $3.00(2.73)$ & $0-9$ & $2.00(1.77)$ & $0-6$ \\
\hline
\end{tabular}




\section{Continued}

Coping: Distraction

Control

Coping: Palliative

Control

Experimental

Coping: Instrumental

Control

Experimental

Coping: Emotional

\section{Control}

Experimental
Experimental

$27.00(2.51)$

28.13 (1.95)

$23-31$

$26.38(3.33)$

$21-30$

$26-32$

$27.00(1.92)$

$24-30$

$28.00(2.14)$

$26-31$

28.63 (2.56)

$24-31$

26.63 (1.85)

$24.29 \quad 29.00(2.27)$

$25-32$

Note $\mathrm{N}=16$ ( $\mathrm{n}=8$ for each group).

Table 3. Comparison of the results in the psychological variables of the pretest and the posttest (Wilcoson rank sum test).

\begin{tabular}{|c|c|c|}
\hline & $\mathrm{Z}$ & Asymptotic Sig. (bilateral) \\
\hline \multicolumn{3}{|l|}{ Anxiety } \\
\hline Control & -0.282 & 0.778 \\
\hline Experimental & -1.620 & 0.105 \\
\hline \multicolumn{3}{|l|}{ Depression } \\
\hline Control & -0.539 & 0.590 \\
\hline Experimental & -1.807 & 0.071 \\
\hline \multicolumn{3}{|c|}{ Coping: Distraction } \\
\hline Control & -0.686 & 0.493 \\
\hline Experimental & -1.051 & 0.293 \\
\hline \multicolumn{3}{|c|}{ Coping: Palliative } \\
\hline Control & -0.677 & 0.498 \\
\hline Experimental & -1.897 & 0.058 \\
\hline \multicolumn{3}{|c|}{ Coping: Instrumental } \\
\hline Control & -2.207 & 0.027 \\
\hline Experimental & -1.361 & 0.174 \\
\hline \multicolumn{3}{|c|}{ Coping: Emotional } \\
\hline Control & -0.070 & 0.944 \\
\hline Experimental & -1.947 & 0.051 \\
\hline
\end{tabular}

a. Sample of a Table footnote (Table footnote is dispensable). 
depression variable. However, a slight difference was observed as a treatment effect between the groups in favor of the experimental group, although it was not statistically significant, it was close to the cut-off point $(p=0.07)$.

Regarding Coping Strategies, in the pretest control group the Palliative style had the highest score (patients seek to alleviate the discomfort of the situation by changing the environment, for example, resting $)(\mathrm{M}=28, \mathrm{SD}=2.14)$, followed by Distraction style (patients take actions to avoid concern about their health) $(\mathrm{M}=27, \mathrm{SD}=2.51)$, then Instrumental style (patients focus on various task-oriented strategies used to treat illness $)(\mathrm{M}=24.13, \mathrm{SD}=1.88)$, and Emotional style (patients focus on emotional consequences and concerns of the health problem), $(\mathrm{M}=18.13, \mathrm{SD}=2.99)$. In the post-test, the Palliative style ( $\mathrm{M}$ $=28.63, \mathrm{SD}=2.56)$ continues to predominate, but the use of the Instrumental style $(\mathrm{M}=27.25, \mathrm{SD}=3.01)$ and Distraction style $(\mathrm{M}=26.38, \mathrm{SD}=3.33)$ increases, with the Emotional style being the less frequent in use $(\mathrm{M}=19.13, \mathrm{SD}=$ 7.31) (Table 2).

In the Coping Strategies, in the experimental group in the pretest the Distraction $(M=28.13, S D=1.95)$, Instrumental $(M=26.88, S D=5.25)$, Palliative ( $M$ $=26.63, \mathrm{SD}=1.88)$, Emotional styles were most reported $(\mathrm{M}=20.13, \mathrm{SD}=$ $6.27)$. In the post-test, the Palliative style $(M=29, S D=2.27)$ was the most reported, then the Instrumental $(\mathrm{M}=28.25, \mathrm{SD}=3.11)$, Distraction $(\mathrm{M}=27, \mathrm{SD}=$ 1.92), and the least used was the Emotional style $(\mathrm{M}=15.88, \mathrm{SD}=3.27)$ (Table 2).

A significant difference is observed as a treatment effect between the groups in favor of the experimental group in the greater use of the Palliative coping style $(p=0.05)$ and less predominance of the Emotional style $(p=0.05)$ (Table 3$)$.

\section{Discussion}

The aim of this study was reached because it was determined the efficacy of a psychological preparation program with a cognitive behavioral intervention to reduce levels of anxiety and depression in addition to modifying the coping style of patients with heart disease tributary of a surgical intervention with cardiopulmonary bypass.

Patients who undergo cardiopulmonary bypass surgery received a complex surgical procedure, with a higher risk of complications, under general anesthesia, and required a prolonged recovery time, which is why they constituted a population at risk of presenting psychological alterations.

For example, the results of the Anxiety variable showed a prevalence to some degree in both groups before surgery, similar to data reported by Talavera-Peña et al. (2020) and Moreno and Calle (2015). In this research, the causes of attributions of the presence of anxiety were not evaluated, however, the explanations of Hernández, et al. (2016), can be assumed since they also worked with patients undergoing high-risk cardiovascular surgery: fear of pain and to the different circumstances of the intervention, depend temporarily on their family to carry 
out daily activities, changes in their body image, the use of anesthesia and thinking of the possibility of dying. Preoperative anxiety has also been related in these patients with the appearance of surgical complications such as: prolongation of hours of mechanical ventilation, greater hemodynamic variability, higher levels of postoperative pain and increased analgesic and anesthetic consumption, higher incidence of confusional syndrome and lower final patient satisfaction (Fernández et al., 2012).

Regarding the Depression variable, only mild to moderate levels were reported in the experimental group. These data are consistent with patients who were candidates for coronary artery bypass grafting where depression was present in $36 \%$ of the patients, and with patients with unstable angina pectoris where the prevalence of depression was 14\% and 47\% (Hweidi et al, 2018; Ramesh et al. 2016; Tully, 2012). Like previous research, Nemati and Astaneh (2011), point out the need to evaluate depression in coronary patients.

They reported that these patients had an increase in hospital stay, a poorer evolution, it is a risk factor of new heart attacks and the appearance of heart rhythm disorders, adding a later recovery of the patients, functional deterioration and a worse quality of life, prevalence of chronic postoperative pain and hospital readmissions. Furthermore, Watkins et al. (2013), point out that patients with coronary heart disease with a prevalence of anxiety have twice the risk of mortality compared to those who do not, and the increase in risk is more pronounced in the group of patients with anxiety and depression, presenting a risk of mortality three times higher. Patients with preoperative anxiety also reported the appearance of surgical complications such as: prolongation of hours of mechanical ventilation, greater hemodynamic variability, higher levels of postoperative pain and in-creased analgesic and anesthetic consumption, higher incidence of confusional syndrome and lower final patient satisfaction (Fernández et al., 2012).

These findings showed the need to include a psychologist to be responsible of the management of these psychosocial variables in the multidisciplinary teams of specialists for the care of these patients. In contrast, cardiac rehabilitation programs that are only based on physical activity do not reduce the levels of anxiety or depression of patients (Arefizadeh, Hariri, \& Moghadam, 2017).

Regarding coping, in both groups adequate strategies were reported since the patients were active and, in some way, oriented to the problem, seeking to reduce their discomfort and showing behaviors to avoid worry. Even so, a significant difference was found as a treatment effect in favor of the experimental group in the greater use of the Palliative coping style $(p=0.05)$ and less predominance of the Emotional style $(p=0.05)$, that is, in the palliative style patients engage in self-help responses to alleviate the discomfort of the situation, for example, make the environment comfortable, rest more, etc., while in the Emotional style patients decrease their focus more on the emotional consequences of their disease, for example, modify their fantasizing and self-concern responses. 
In this sense, Jackson and Emery (2013) and Roohafza et al. (2012) reported that patients in cardiac rehabilitation, the active coping style was related to better cardiovascular health. In other words, although the organism presents a cardiovascular reactivity to stress, it returns more quickly to its basal state, compared to the coping style focused on emotion. In addition, they also reported that the immune system was more resistant under stress situations, with shorter hospital stay and lower mortality and had a favorable effect on anxiety symptoms. In contrast, patients who reported passive emotional coping were more consistent with the belief that they have no control over the disease, feel angry, frustrated, spend time thinking about what they cannot do to control the disease. They fantasize about being healthy, wish it hadn't happened to them, think themselves defenseless, and tend to stay longer in cardiac rehabilitation programs.

The main limitation of this study is the very small sample size, so the results are not generalizable. The type of occupation of the participants was not considered either. The levels of anxiety or depression of patients who are going to have surgery can be altered, among other factors, by the uncertainty of whether they will be able to return to their work environment after surgery (Larrinaga et al., 2016).

\section{Conclusion}

In conclusion, it is essential that the psychologist specialized in behavioral cardiology develops and carries out interventions in order to empower the patient with cognitive, emotional and behavioral skills called coping strategies, in particular with emotional coping and management of anxiety and depression.

\section{Funding}

This study was supported by PAPIIT IN 309219, DGAPA, UNAM.

\section{Conflicts of Interest}

The authors declare no conflicts of interest regarding the publication of this paper.

\section{References}

Arefizadeh, R., Hariri, S. Y., \& Moghadam, A. J. (2017). Outcome of Cardiac Rehabilitation Following Off-Pump versus On-Pump Coronary Bypass Surgery. Open Access Macedonian, Journal of Medical Sciences, 5, 290-294. https://doi.org/10.3889/oamjms.2017.057

Beresnevaite, M., Benetis, R., Taylor, G. J., Rašinskienè, S., Stankus, A., \& Kinduris, S. (2016). Impact of a Cognitive Behavioral Intervention on Health-Related Quality of Life and General Heart Rate Variability in Patients Following Cardiac Surgery: An Effectiveness Study. Psychosomatics, 57, 605-615.

https://doi.org/10.1016/j.psym.2016.04.004

Castillero, Y. (2007). Intervención psicológica en cirugía cardíaca. Avances en Psicología 
Lationamericana, 25, 52-63. http://www.scielo.org.co/pdf/apl/v25n1/v25n1a6.pdf

Crandall, W. V., Halterman, T. E., \& Mckner, L. M. (2007). Anxiety and Pain Symptoms in Children with Inflammatory Bowel Disease and Functional Gastrointestinal Disorders Undergoing Colonoscopy. Journal of Pediatric Gastroenterology \& Nutrition, 44, 63-67. https://doi.org/10.1097/01.mpg.0000239733.79487.1e

Endler, N., Parker, D., \& Summerfeldt, J. (1998). Coping with Health Problems: Developing a Reliable and Valid Multidimensional Measure. Psychological Assessment, 10, 195-205. https://doi.org/10.1037/1040-3590.10.3.195

Fernández, A., Jiménez, J., Bodi, V., \& Barrabés, J. (2012). Actualización en cardiopatía isquémica. Revista Española de Cardiología, 65, 42-49.

https://doi.org/10.1016/j.recesp.2011.10.031

Hernández, A., López, A., \& Guzmán. J. (2016) Nivel de ansiedad e información preoperatoria en pacientes programados para cirugía. Un estudio transversal descriptivo. Acta Médica Grupo Ángeles, 14, 6-11.

Hweidi, I. M., Gharaibeh, B. A., Al-Obeisat, S. M., \& Al-Smadi, A. M. (2018). Prevalence of Depression and Its Associated Factors in Patients Post-Coronary Artery Bypass Graft Surgery. Journal of Research in Nursing, 23, 76-88.

https://doi.org/10.1177/1744987117728314

Instituto Nacional de Estadística y Geografía (INEG) (2021). Características de las defunciones registradas en México durante Enero a Agosto de 2020. [comunicado de prensa]

https://www.inegi.org.mx/contenidos/saladeprensa/boletines/2021/EstSociodemo/Defu ncionesRegistradas2020 Pnles.pdf

Jackson, J. L., \& Emery, C. F. (2013). Emotional Distress, Alexithymia, and Coping as Predictors of Cardiac Rehabilitation Outcomes and Attendance. Journal of Cardiopulmonary Rehabilitation and Prevention, 33, 26-32.

https://doi.org/10.1097/HCR.0b013e318276864c

Larrinaga, V., Hernández, E., Hernández, D., \& Crespo, I. (2016). Características sociodemográficas y estados emocionales negativos en pacientes con enfermedad cardiovascular con indicación quirúrgica. CorSalud, 8, 164-172.

http://www.revcorsalud.sld.cu/index.php/cors/article/view/136/324

Lazarus, R. S., \& Folkman, S. (1986). Estrés y procesos cognitivos. Martínez Roca.

Moreno, P., \& Calle, A. (2015). Detección y actuación en la ansiedad preoperatoria inmediata. De la teoría a la práctica. Cirugía mayor ambulatoria, 20, 74-78. http://www.asecma.org/Documentos/Articulos/06 20 2 OR Moreno.pdf

Nemati, M. H., \& Astaneh, B. (2011). The Impact of Coronary Artery Bypass Graft Surgery on Depression and Anxiety. Journal of Cardiovascular Medicine, 12, 401-404. https://doi.org/10.2459/JCM.0b013e32834358e9

Niknejad, R., Mirmohammad-Sadeghi, M., Akbari, M., \& Ghadami, A. (2019). Effects of an Orientation Tour on Preoperative Anxiety in Candidates for Coronary Artery Bypass Grafting: A Randomized Clinical. Arya Atherosclerosis, 16, 154-160.

http://arya.mui.ac.ir/index.php/arya/article/view/1806

Organización Mundial de la Salud (OMS) (2020, 9 de diciembre). Las 10 principales causas de defunción.

https://www.who.int/es/news-room/fact-sheets/detail/the-top-10-causes-of-death

Ramesh, C., Nayak, B. S., Pai, V. B., Patil, N. T., George, A., George, L. S., \& Devi, E. S. (2016). Effect of Preoperative Education on Postoperative Outcomes among Patients Undergoing Cardiac Surgery: A Systematic Review and Meta-Analysis. American So- 
ciety of Perianesthesia Nurses, 32, 518-529.E2.

https://doi.org/10.1016/j.jopan.2016.11.011

https://www.jopan.org/article/S1089-9472(16)30422-1/fulltext

Reavell, J., Hopkinson, M., Clarkesmith, D., \& Lane, D. A. (2018). Effectiveness of Cognitive Behavioral Therapy for Depression and Anxiety in Patients with Cardiovascular Disease: A Systematic Review and Meta-Analysis. Psychosomatic Medicine, 80, 742-753. https://doi.org/10.1097/PSY.0000000000000626

Reyes, A., \& González, B. (2002). Derivación cardiopulmonar en el paciente con enfermedades renales. Revista Mexicana de Enfermería Cardiológica, 10, 38-41. https://www.medigraphic.com/pdfs/enfe/en-2002/en021f.pdf

Rodríguez, G. (2000). Programa de pacientes para procedimientos médicos invasivos y quirúrgicos. Aspectos cognitivos y conductuales. Miguel Ángel Porrúa

Roohafza, M., Talaei, M., Pourmoghaddas, Z., Rajabi, F., \& Sadeghi, M. (2012). Association of Social Support and Coping Strategies with Acute Coronary Syndrome: A Case-Control Study. Journal of Cardiology, 59, 154-159. https://doi.org/10.1016/j.jicc.2011.12.001

Snaith, R. P. (2003). The Hospital Anxiety and Depression Scale. Health and Quality of Life Outcomes, 1, Article No. 29. https://doi.org/10.1186/1477

Talavera-Peña, A. K., Vargas-Nuñez, B. I., Figueroa-López, C. G., García-Méndez, M., \& Meda-Lara, R. M. (2020). Psychoeducational Intervention to Modify Anxiety, Depression, and Quality of Life in Candidates for Coronary Artery Bypass. Psicología y Salud, 30, 59-71. https://doi.org/10.25009/pys.v30i1.2618

Tully, P. J. (2012). Psychological Depression and Cardiac Surgery: A Comprehensive Review. The Journal of Extra-Corporeal Technology, 44, 224-232.

Watkins, L. L., Koch, G. G., Sherwood, A., Blumenthal, J. A., Davidson, J. R. T., O'Connor, C., \& Sketch, M. H. (2013). Association of Anxiety and Depression with All-Cause Mortality in Individuals with Coronary Heart Disease. Journal of the American Heart Association, 2, Article ID: e000068. https://doi.org/10.1161/JAHA.112.000068

Zigmond, A., \& Snaith, R. (1983). The Hospital Anxiety and Depression Scale. Acta Psychiatr Scand, 67, 361-370. https://doi.org/10.1111/j.1600-0447.1983.tb09716.x 